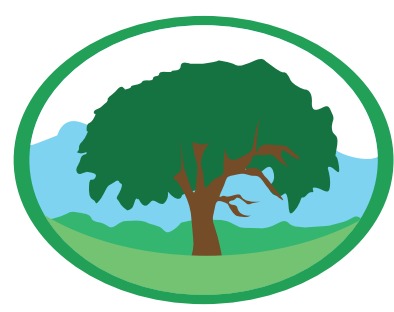

\title{
ANÁLISE TEÓRICO-EXPERIMENTAL DA MICROESTRUTURA DO AC̣O AISI 316L SOLDADO VIA GTAW COM DIFERENTES METAIS
}

\author{
CORREIO, T. A. V. ${ }^{1}$; REICHERT, A. A. ${ }^{1}$; OSÓRIO, A. G. ${ }^{1}$; SOUZA, D. ${ }^{2}$. \\ ${ }^{1}$ Universidade Federal de Pelotas \\ ${ }^{2}$ Universidade Federal do Rio Grande
}

Palavras-chave: aços inoxidáveis, gtaw, diagrama de schaeffler.

\section{Resumo}

0 metal AISI 316L soldado via GTAW, utilizando os metais de adição ER 316L Si e ER 420, com objetivo de comparação teórica e prática da microestrutura obtida por esta soldagem. Para a avaliação teórica, foi utilizado o diagrama de Schaeffler. Em uma primeira etapa foi determinada a taxa de diluição e energia de soldagem e em seguida, identificou-se via Microscopia Óptica (MO), as fases resultantes das peças soldadas. Estas fases foram comparadas com as fases indicadas pelo diagrama de Schaeffler. No MO observou-se a presença de bandas no metal base (MB), provocada pelo alto percentual de manganês. Para a peça soldada com o ER $316 \mathrm{~L} \mathrm{Si}$, identificou-se $44 \%$ de diluição e energia de soldagem de $256,5 \mathrm{~J} / \mathrm{cm}$, já a solda realizada com o ER 420 teve $30 \%$ de diluição, com energia de soldagem de $259,5 \mathrm{~J} / \mathrm{cm}$. As porcentagens das fases na zona fundida (ZF) com o metal de adição ER 420 foram de $2 \%$ de martensita e $98 \%$ de austenita, de acordo com os resultados teóricos esperados. Para as soldas realizadas com o metal de adição ER $316 \mathrm{~L} \mathrm{Si,}$ encontrou-se pelo diagrama $8 \%$ de ferrita e $92 \%$ de austenita, não sendo compatível com o resultado prático obtido, que indicou $61 \%$ de ferrita e $39 \%$ de austenita.

\section{THEORETICAL-EXPERIMENTAL ANALYZE OF THE MICROSTRUCTURE OF AN AISI 316L STEEL WELDED BY GTAW WITH DIFFERENT METALS}

Keywords: stainless steels, gtaw, schaeffler diagram.

\begin{abstract}
The AISI 316L plate was welded via GTAW, using ER 316L Si and ER 420 as addition metal, with the main purpose of perform a theoretical and practical evaluation of the microstructure obtained in these welds. Theoretical evaluation was performed via Schaeffler diagram., the dilution rate and welding energy were determined. Afterwards, the resulting phases of the welded parts were identified via Optical Microscopy (OM). These phases were compared to the phases indicated in the Schaeffler diagram. This study found for the welded part with the ER $316 \mathrm{~L} \mathrm{Si,} \mathrm{44 \%}$ dilution and welding energy of $256.5 \mathrm{~J} / \mathrm{cm}$, whereas the weld that used the ER 420 presented only $30 \%$ of dilution, with welding energy of $259.5 \mathrm{~J} / \mathrm{cm}$. The percentages of the phases in the melt zone (ZF) with the ER 420 addition metal were $2 \%$ martensite and $98 \%$ austenite, according to the results expected by the Schaeffler diagram. For welds made with the ER 316 L Si addition metal, 8\% ferrite and 92\% austenite were expected according to the Schaeffler diagram, not compatible with the practical results obtained, which indicated $61 \%$ of ferrite and $39 \%$ of austenite.
\end{abstract}




\section{INTRODUÇÃO}

O aço austenítico é um tipo de liga da categoria dos aços inoxidáveis. Este tipo de aço é utilizado mais frequentemente devido a sua tenacidade, ductilidade e resistência à corrosão, superiores à da maioria dos outros aços (S. Shashi Kumar, 2017).

Na soldagem GTAW (Gas-Shielded Tungsten Arc Welding), criado em 1930 e desenvolvido em 1941, o processo utiliza um eletrodo de tungstênio náo consumível e gás inerte para proteção, sendo possível realizar o controle estrutural da uniáo soldada (Lucas, 1990). O calor e a alta energia do arco presentes durante a soldagem de aços austeníticos permite a precipitação de carbonetos e também a formação de carbonetos de cromo (Soltani, 2018).

$\mathrm{Na}$ zona fundida de soldas de aços inoxidáveis austeníticos contém uma variação de estruturas austenítica e ferrítica, dependendo do comportamento no momento da solidificaçáo. Pelo processo GTAW obtêm-se, na maioria dos casos, microestrutura totalmente ferrítica ou totalmente ferrítico/austenítica (M. Alali, 2017).

A microestrutura de uma peça sofre modificações quando há processos de soldagem envolvidos, os quais impactam no desempenho mecânico e consequentemente no seu tempo de vida útil. A fim de mitigar esses problemas e obter uma boa relação entre resistência e tenacidade, se fazem necessários estudos microestruturais entre o metal de base e os metais de adição que foram escolhidos para tal processo (ALBUQUERQUE, 2011).

O presente trabalho visa avaliar a microestrutura obtida das peças soldadas com dois diferentes materiais de adição: ER 316L Si e ER 420, no metal base AISI 316L, e fazer a comparação dos resultados obtidos com o esperado teoricamente, a partir do diagrama de Schaeffler.

\section{MATERIAL E MÉTODOS}

\section{-MATERIAS}

O metal base utilizado para o processo de soldagem GTAW, foi o AISI 316L soldado com o eletrodo revestido 316L Si e outra amostra com eletrodo revestido 420, ambos com a alimentaçáo à frio. A seguir, na tabela 1 , é apresentada a composição química do metal base e dos metais de adição.

Tabela 1. Composição química do metal base e eletrodos.

\begin{tabular}{|l|l|l|l|l|l|l|}
\hline Material & $\% \mathrm{C}$ & $\% \mathrm{Si}$ & $\% \mathrm{Mn}$ & $\% \mathrm{Cr}$ & $\% \mathrm{Ni}$ & $\% \mathrm{Mo}$ \\
\hline AISI 316L & 0,03 & 0,75 & 2,00 & 18,00 & 14,00 & 3,00 \\
\hline ER 316LSi & 0,02 & 0,80 & 1,70 & 18,40 & 12,40 & 2,80 \\
\hline ER 420 & 0,30 & 0,48 & 0,45 & 13,00 & 0,5 & 0,40 \\
\hline
\end{tabular}

Fonte: FAVORITE Aços especiais, TECHNO ALLOYS, BÖHLER WELDING

\section{-MÉTODOS}

Os parâmetros de soldagem previamente estipulados foram: velocidade de solda de $12 \mathrm{~cm} / \mathrm{min}$, velocidade de alimentaçáo de $3 \mathrm{~m} / \mathrm{min}$, distância eletrodo/peça de $9 \mathrm{~mm}$, diâmetro do eletrodo (WT2/TL) de 1,6 mm, e Argônio puro foi utilizado para proteção da solda. Corrente de $180 \mathrm{~A}$ e tensão de $17,3 \mathrm{~V}$ foram utilizadas para o eletrodo 420 , e de $17,1 \mathrm{~V}$ para o eletrodo $316 \mathrm{~L}$ Si mantendo a mesma corrente.

\section{Preparaçáo Metalográfica}

As amostras foram lixadas manualmente para remoção de óxidos superficiais, sob refrigeração em lixadeira manual utilizando papéis abrasivos de granulometria crescente seguindo a ordem 80, 400, 600, 1000 e 1200. Posteriormente, as amostras foram polidas utilizando alumina em suspensão de granulometria média de $1 \mu \mathrm{m}$ como abrasivo fazendo o uso de uma Politriz da marca AEROTEC. A fim de revelar a microestrutura, a amostra foi atacada com água-régia, uma mistura de ácido clorídrico e ácido nítrico na proporção de 3:1, durante 5 minutos. Após o ataque, imagens da microestrutura das amostras foram obtidas por microscópio óptico (MO) Olympus BX41M e posteriormente avaliadas.

\section{Diluiçáo e Penetraçáo}

A diluição é utilizada para achar os pontos no diagrama, a partir dos pontos de $\mathrm{Cr}$ e $\mathrm{Ni}$ equivalentes, traça-se um segmento de reta unindo esses dois pontos. Em seguida, o segmento de reta é dividido em 10 partes iguais, que representam a diluição do processo de soldagem a ser empregado. Partindo do $0 \%$ de diluição no ponto que corresponde ao metal de adição.

Para o cálculo de diluição e penetração do metal de 
Para o cálculo de diluição e penetração do metal de adição no metal base foi utilizado o software de imagens ImageJ, com o objetivo de obter a área de penetração e a área total do cordão. A equação 1 foi utilizada para estes cálculos. Para calcular a penetração, foi aferida a distância entre o ponto de maior profundidade da Zona fundida até o início do reforço da solda.

$$
\frac{A P}{A T} \cdot 100(1)
$$

Sendo:

AP: Área de penetração AT: Área total do cordão

\section{Diagrama de Schaeffler}

Com a finalidade de prever a microestrutura na ZF, utilizou-se os valores indicados na tabela 2 , de acordo com a composição química do metal base e dos metais de adição, fornecidas pelos fabricantes. Os valores de $\mathrm{Ni}$ equivalente e $\mathrm{Cr}$ equivalente foram calculados pelas equaçôes 2 e 3 .

$$
\begin{aligned}
& \text { Creq : } \mathrm{Cr}+\mathrm{Mo}+1,5 \mathrm{Si}+0,5 \mathrm{Nb}(2) \\
& \text { Nieq : } \mathrm{Ni}+30 \mathrm{C}+0,5 \mathrm{Mn}(3)
\end{aligned}
$$

\section{Propriedades Magnéticas}

Com o objetivo de corroborar a composição da microestrutura do metal base AISI 316L, com ER 316L Si e ER 420, como sendo austenítica e martensítica respectivamente, foi realizado teste com um imá para verificar se as amostras em questáo apresentam alguma resposta magnética.

\section{J}

Cálculo de área pelo software de imagens Image

O software Image J foi utilizado com o objetivo de calcular a porcentagem de área das fases de austenita e ferrita da zona fundida do aço inox 316L soldado com ER 316L Si. Utilizou-se o método de limiarização de imagem, que se baseia na diferença de cores entre as fases.

\section{RESULTADOS E DISCUSSÃO}

\section{Diluição}

Segundo os dados de área obtidos pelo software Image J, segue o cálculo de diluição:

Diluição do ER 420:

$$
\frac{A P}{A T} \cdot 100=\frac{0,09}{0,3} \cdot 100=30 \%
$$

Diluição do ER 316L Si:

$$
\frac{A P}{A T} \cdot 100=\frac{0,123}{0,279} \cdot 100=44 \%
$$

\section{Diagrama de Schaeffler}

A partir das equaçóes 3 e 4 obteve-se os seguintes resultados, apresentados na tabela 2 .

Tabela 2. Resultados de $\mathrm{Cr}$ e Ni equivalente.Material

\begin{tabular}{|l|l|l|}
\hline Materiais & \multicolumn{1}{|c|}{ Cr eq } & Ni eq \\
\hline AISI 316L & 22,12 & 15,90 \\
\hline ER 316L Si & 22,40 & 13,85 \\
\hline ER 420 & 14,12 & 9,72 \\
\hline \multicolumn{2}{|c|}{ Fonte: Próprio autor }
\end{tabular}

A figura 1 apresenta o Diagrama de Schaeffler, com indicação das fases esperadas, para as composiçóes químicas consideradas. . O valor teórico mostrado no gráfico da figura 1 , no ponto P1 é correspondente ao metal de adiçáo ER 316L Si, e indica a presença de $8 \%$ de ferrita e $92 \%$ de austenita. No ponto P2 correspondente ao metal de adição ER 420, indica-se a presenta de $2 \%$ de martensita e $98 \%$ de austenita.

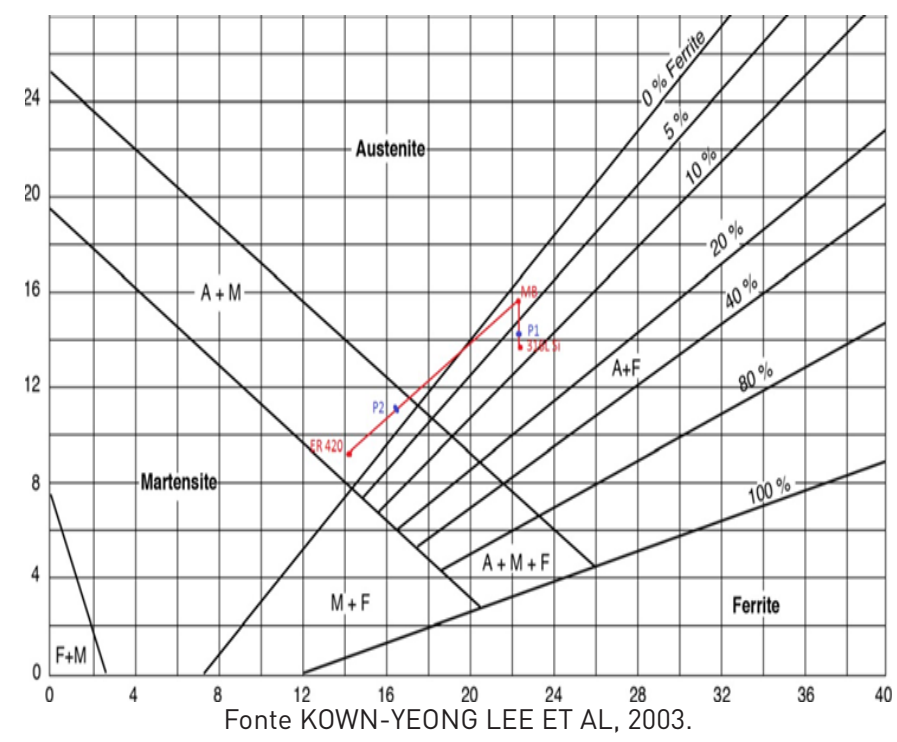

\section{Análise de imagem por microscopia ótica}

A figura 2 apresenta imagens da microestrutura obtida para as unióes soldadas com ER 420. Observase uma fase dominante que seria a austenita e outra fase pouco presente que seria a martensita, o que condiz com os valores teóricos encontrados para esta solda a partir do diagrama de Schaeffler. 

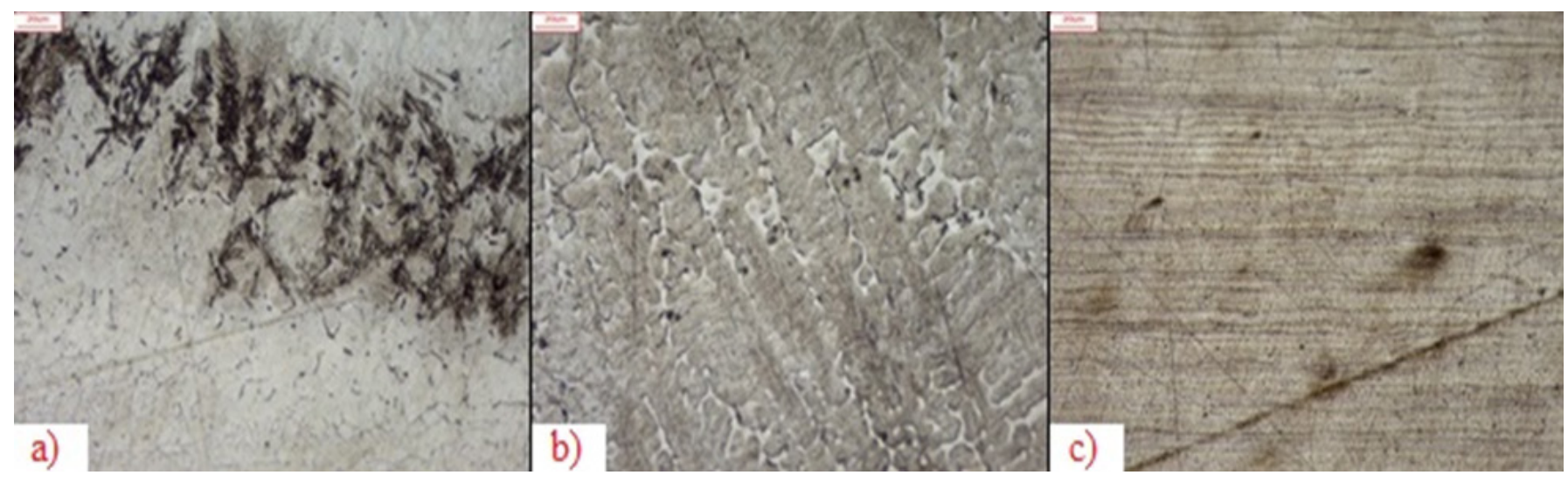

Figura 2.Micrografia obtida via MO da ZT (a), ZF (b) e MB (c) do aço inox 316L soldado com ER 420, com aumento de 200x. Ataque: água-régia - 5 min. Fonte: Próprio autor.

A figura 3 apresenta as micrografias obtidas para os corpos de prova soldados com ER 316L Si. Nestas imagens é possível verificar uma distribuição homogênea das fases, o que não confere com as porcentagens teóricas de fases esperadas pelo diagrama de Schaeffler.

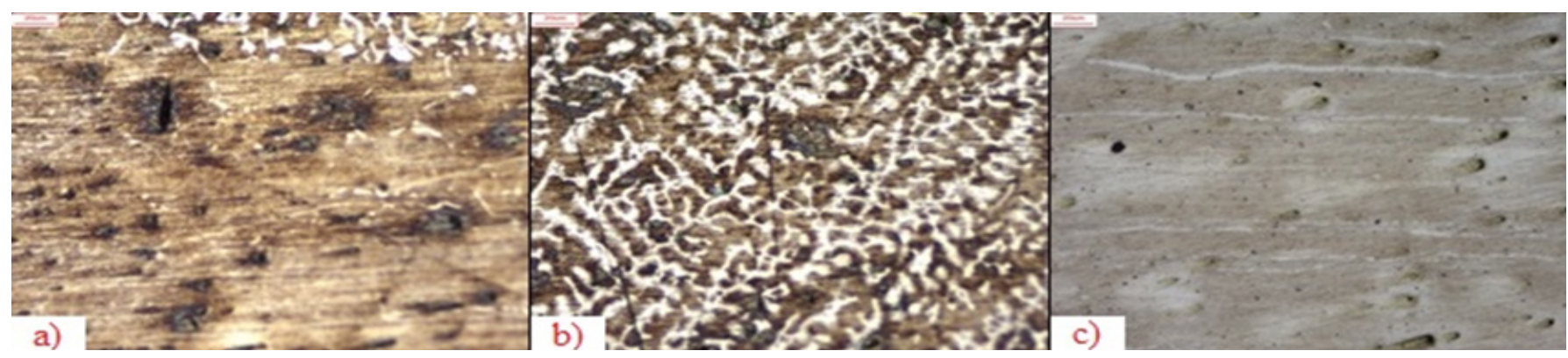

Figura 3. Micrografia obtida via MO do ZT (a), ZF (b) e MB (c) do aço inox $316 \mathrm{~L}$ soldado com ER 316L Si, com aumento de 200x. Ataque: água-régia - 5 min. Fonte: Próprio autor.

As figuras 2(c) e 3(c), apresentam inclusóes de sulfeto de manganês de forma alongada em toda extensão do MB. As mesmas podem ser justificas pela grande porcentagem de manganês utilizado para proteção por fragilização de enxofre (LIMA, 2010; MARQUEZI, 2013).

Cálculo para \% de área pelo software Image J

Para avaliar a porcentagem exata de cada fase da solda do aço inoxidável 316L soldado com ER 316L $\mathrm{Si}$, foi feito um tratamento de imagem, mostrado na figura 4, que apresenta a micrografia (b) referente à imagem limiarizada do aço inox 316L soldado com ER 316L Si. Esta análise revela 61\% da fase em branco, correspondente a fase escura na micrografia (a), restando 39\% da fase em preto referente a fase em branco da micrografia (a). Portanto, a estrutura da micrografia (a) é composta pela fase austenita (cor clara) e ferrita (cor escura) (Gunn,1997).

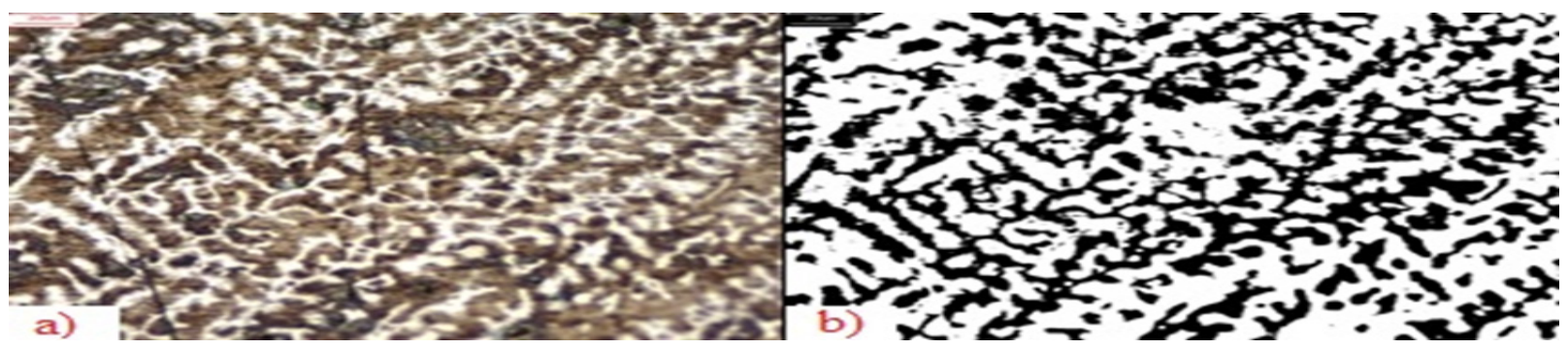

Figura 4. Micrografia do aço inox $316 \mathrm{~L}$ soldado com ER 316LSi (a), micrografia limiarizada do aço inox 316L soldado com ER 316LSi calculada pelo aplicativo Image J. Fonte: Próprio autor. 


\section{Propriedades Magnéticas}

Sabe-se que estruturas austeníticas são nãomagnéticas, então utilizou-se deste conhecimento para realizar um teste simples de aproximação de um imá aos cordóes de solda, para verificar a interação deste com os cordóes. Como pode ser visualizado na figura 5, o aço 316L soldado com ER 420 (a) apresentou grande interação do imã com o cordão de solda, indicando uma resposta magnética desde cordão. Este resultado está de acordo com o esperado, tendo em vista que aços da série 400 apresentam propriedades magnéticas características. Já as uniōes soldadas com ER 316L Si (b) não apresentaram uma grande interação do imã com o cordão de solda, apresentando uma fraca atração magnética, o que corrobora com dados de literatura para os aços da série 300, que são austeníticos (TULER. et al., 2016; GIRALDO, S. et al., 2010).

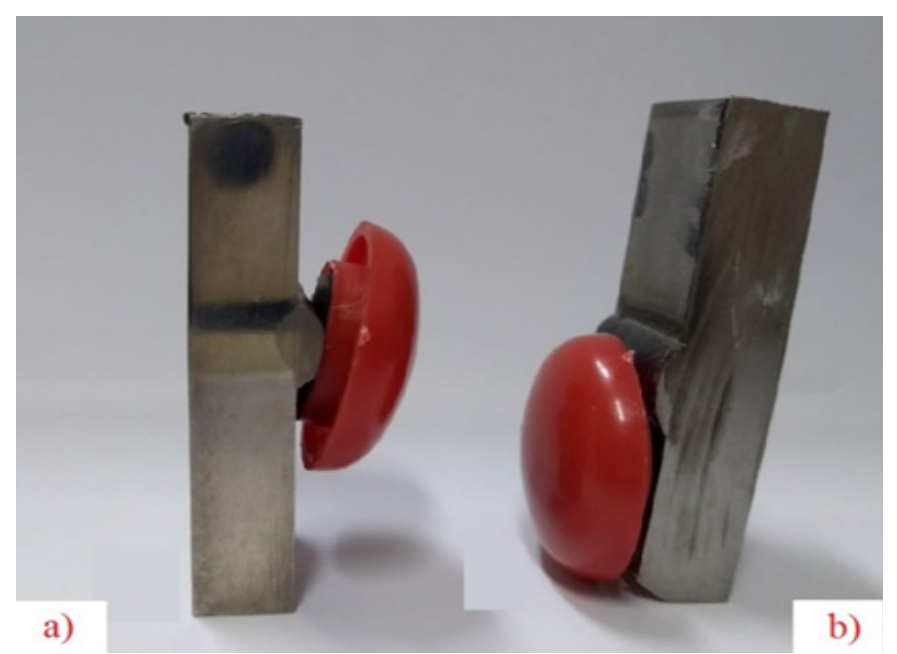

Figura 5. Teste de magnetismo. Aço inox $316 \mathrm{~L}$ soldado com ER 420 (a), aço inox 316L soldado com ER 316L Si (b) Fonte: Próprio autor.

\section{CONCLUSÃO}

A partir do presente estudo é possível aferir que as fases microestruturais obtidas para a solda com o metal de adiçáo ER 420 foram de 2\% de martensita e 98\% de austenita, tanto pelo digrama de Schaeffler, quanto pelas micrografias obtidas de forma experimental. Já as soldas realizadas com o metal de adição ER 316L Si, apresentaram divergência nos dados teóricos com os experimentais, sendo $8 \%$ de ferrita e $92 \%$ de austenita pelo diagrama e $61 \%$ de ferrita e $39 \%$ de austenita pelas micrografias e tratamento de imagem.

\section{LITERATURA CITADA}

ALALI, M. Through-thickness microstructure and mechanical properties of electron beam welded $20 \mathrm{~mm}$ thick AISI 316L austenitic stainless steel (2017).

ALBUQUERQUE, Siderley Fernandes et al. Avaliaçáo da microestrutura e propriedades mecânicas de metais de solda obtidos por processos de soldagem manual e automatizado utilizado na soldagem de aço API 5L X80. Soldag. Insp., São Paulo, v. 16, n. 4, p. 322-332, Dez. 2011.

\section{FAVORITE AÇOS ESPECIAIS. Disponível} em: <http://www.favorit.com.br/produtos/acos-inoxidaveis/acoaisi-316-aisi-316-1> Acesso em: 12. Jun. 2018.

GIRALDO, S. P. C; PADOVESE, R.L. Avaliaçáo de Soldagem de Aço Estrutural através do Ruído Magnético de Barkhausen. Soldagem \& Inspeção (Impresso), v.15, n.4, p.273-280, 2010.

GONCALVES, R. B. ET AL. Efeito do Tratamento Térmico de Solubilizaçáo e Estabilizaçáo na microestrutura de uma Junta Soldada com Aço Inox 347. Matéria (Rio J.) [online]. 2017, vol.22, n.1.

GONCALVES, R. B. ET AL. Estabilizaçáo na microestrutura de uma Junta Soldada com Aço Inox 347. Matéria (Rio J.), Rio de Janeiro, v. 22,n. 1,e11784, 2017.

GUNN, R. N.; Duplex Stainless Steel: Microstructures, Properties and Applications. Abington, $1^{\circ}$ edition, 1997, page 118.

KOWN-YEONG, L. ET AL. The effects of additive elements on the sliding wear behavior of Fe-base hardfacing alloys, Wear, 2003.

KUMAR, S.S. Microstructure and Mechanical Properties of Friction Stir Welded AISI 316L Austenitic Stainless Steel Joints (2017).

LUCAS W. TIG and Plasma Welding. 1- edição, Cambridge England, Abington Publishing. 1990, p. 3-25.

MARQUEZI, S.L. LIMA, L. I. L. et al. Caracterizaçáo microestrutural de soldas dissimilares dos aços ASTM A-508 e AISI 316L. Soldag. insp. (Impr.) vol.15 no.2 São Paulo Apr./ June 2010.

MARQUEZI, S.L; BAGETTI, J. H; PRIOR, M. Análise do grau de contaminaçáo com carbono do aço inoxidável astm a743 ca6mn em razáo do tratamento térmico de alívio de tensóes em conjunto com aço carbono. Unoesc \& Ciência ACET, Joaçaba, v. 4, n. 2, p. 121-138, jul./dez. 2013.

SOLTANI, H.M. TAYEBI, M. Comparative study of AISI 304L to AISI 316L stainless steels joints by TIG and Nd:YAG laser welding. Journal of Alloys and Compounds (2018). 
TECHNO ALLOYS. Disponível em: <http://www.technoalloys.com/site/> Acesso em: 12. Jun. 2018.

TULER ET AL. Resoluçáo do problema do aço inoxidável da empresa Aperam. Revista Científica Univiçosa - Volume 8- n. 1 - Viçosa - MG - Jan. - dez. 2016- p. 848-854.

VOESTALPINE BÖHLER W E L D I N G .

Disponível em:<http://www.voestalpine.com/welding/br/> Acesso em: 12. Jun. 2018

LUCAS W., "TIG and Plasma Welding”, 1- edição, Cambridge - England, Abington

Publishing. 1990, p. 3-25. (NOVO) 